\title{
The training of healthcare professionals: An expense or an investment?
}

\author{
R G MacGregor, ${ }^{1}$ MSc, PhD; G Zihindula, ${ }^{2} \mathrm{MSc}, \mathrm{PhD}, \mathrm{MPH} ; \mathrm{L}$ Chola, ${ }^{3} \mathrm{PhD} ; \mathrm{A} \mathbf{J}$ Ross, ${ }^{4} \mathrm{MB}$ ChB, DCH, FCFP, MMed (Fam Med), PhD \\ ${ }^{1}$ Umthombo Youth Development Foundation, Durban, South Africa \\ ${ }^{2}$ Healthy Rural Society, Mtubatuba, South Africa \\ ${ }^{3}$ School of Public Health, Faculty of Health Sciences, University of the Witwatersrand, Johannesburg, South Africa \\ ${ }^{4}$ Department of Family Medicine, School of Nursing and Public Health, College of Health Sciences, University of KwaZulu-Natal, Durban, \\ South Africa
}

Corresponding author: A J Ross (rossa@ukzn.ac.za)

\begin{abstract}
Background. There is little information on the financial return of investment when funding the tertiary education of healthcare professionals (HCPs) in South Africa (SA).

Objectives. To assess the cost-benefit of the Umthombo Youth Development Foundation (UYDF) scholarship scheme, which has supported the training of HCPs from rural areas in KwaZulu-Natal Province, SA, for the past 19 years, and to establish whether it is a worthwhile investment. Methods. This was an economic analysis to estimate the costs and economic value of UYDF's investment in the training of HCPs, using a deterministic model developed in Excel 2010 (Microsoft, USA) to analyse the UYDF's historical, numerical and economic data. Costs were measured in monetary terms, and a rate of return on investment was calculated over the working life of HCPs who had been supported by the UYDF.

Results. With a $>90 \%$ pass rate, the total cost of training the 254 graduates supported by the UYDF from 2009 to 2015 was estimated to be ZAR186 million. Graduates are expected to generate an estimated ZAR15 billion in lifetime earnings, which is equal to ZAR4 billion at 2015 prices, and represents an internal rate of return of $63 \%$. Income tax paid on future earnings will be $\sim$ ZAR4 billion, assuming a $20-30 \%$ tax rate. Conclusions. The analysis has shown that the cost of HCPs' education, where the annual pass rate is $>90 \%$, and $>98 \%$ of graduates are employed, is an excellent investment. Consideration should be given to finding ways of improving the pass rate at institutions of higher learning and ensuring that graduates obtain meaningful employment if such returns on investment are to be seen on a national level.
\end{abstract}

S Afr Med J 2020;110(5):369-373. https://doi.org/10.7196/SAMJ.2020.v110i5.14221

Many South Africans living in rural areas do not have access to affordable, quality, comprehensive healthcare, despite considerable government investments in programmes to strengthen the healthcare system. In their study, Pillay et al. ${ }^{[1]}$ found that the burden of poverty and disease in South Africa (SA) is highest in rural areas, while Benatar et al. ${ }^{[2]}$ confirmed that public and private health resources are skewed towards urban areas. Within the context of free primary health services, substantial barriers to receiving care remain, as accessing health services can be a challenge ${ }^{[3]}$ owing to high transport costs. More than $15 \%$ of poor rural households live $>1$ hour away from the closest clinic, and $20 \%>1$ hour away from the nearest hospital. ${ }^{[4]}$ Compounding these challenges, is a critical shortage of health workers in SA, as cited by Moyimane et al. ${ }^{[5]}$ In 2013, it was estimated that SA had 60 doctors per 100000 population compared with a global average of $152 / 100000 .{ }^{[4]}$ Large inequalities also exist in the distribution of healthcare resources between rural and urban areas, which exacerbate the challenge of accessing quality healthcare. In 2004, a study conducted by Hamilton and $\mathrm{Yau}^{[6]}$ estimated that only $12 \%$ of doctors and $18 \%$ of nurses were serving $46 \%$ of the national population who lived in rural areas.

These challenges are acknowledged in many government strategies, and are the focus of the proposed National Health Insurance (NHI) and Human Resources for Health strategy, which aim to provide a comprehensive and equitable health service to all South Africans. ${ }^{[7]}$ However, there can be no healthcare without a health workforce, and the dream of universal health coverage cannot be achieved without a considerable injection of resources into the training of healthcare professionals (HCPs). ${ }^{[8]}$

A few studies have investigated the cost of educating HCPs in $\mathrm{SA}$, and have tracked the resources and efforts required to maintain an adequate supply nationally. ${ }^{[9-11]}$ The aim of this article was to assess the financial return on investment of HCP education using data from the Umthombo Youth Development Foundation (UYDF) scholarship scheme to determine whether the costs associated with their education should be viewed as an expense or as an investment.

The UYDF has been supporting rural youth to train as HCPs since 1999, and by the end of 2017, had produced 337 graduates across 16 health disciplines, with an annual pass rate of $>90 \%$ for the past 10 years. $^{[12,13]}$ The aim of the scheme is to address the shortages of qualified HCPs at rural hospitals by identifying, training and supporting rural youth to graduate in various disciplines. The UYDF education and training process involves an integrated model of recruitment at school level, selection at rural hospitals, support during education and training, and employment support and retention on return to the local rural workplace (Fig. 1), the details of which have been previously described by MacGregor et al..$^{[14]}$

\section{Methods}

A desk-top economic analysis was undertaken to calculate the cost of training HCPs who had been supported by the UYDF, with the intention of determining the total financial costs to the scholarship scheme and potential economic return on investment measured as 
future salary benefits and payable income tax. The majority of students supported by the UYDF receive full-cost bursaries that cover tuition, accommodation, books, food, minor equipment and incidental expenses. The analysis involved identifying all costs related to supporting UYDF students, as recorded in its books of accounts and administrative records. The costing was done across 6 major categories that were identified as the main cost centres, according to the UYDF model (Fig. 1). These were: (i) recruitment; (ii) educational support; (iii) mentorship; (iv) postgraduate support; (v) administration; and (vi) capital costs. Recruitment included the costs of school marketing, hospital open days and selection interviews, and half a staff person's salary for activities intended to recruit students. Educational support included university fees, costs of accommodation, books and meals, and other expenses such as equipment, uniforms and professional registration. The opportunity cost of education, which was regarded as the wages forgone in the period that a student stayed at university, was calculated using the annual salary of clerks and cashiers coming straight from school as the proxy. Mentorship included costs related to providing academic and social mentoring support, such as the organisation's full-time mentor (salary, travel and accommodation), stipends and associated costs paid to the network of mentors, and stipends paid to students on completion of holiday work and attendance of the Student Life Skills Imbizo. The administration cost centre managed all costs necessary for running the programme, including salaries of 3 staff members, bookkeeping and auditing, overheads, office rental, communication and travel.

Costing was determined for 2009 - 2015, as full programme and financial data for all aspects of the model were available for this period and the UYDF had moved from a volunteer-run organisation to an organisation with employees in 2008. The costs were classified as recurrent or capital, the former including items such as stationery, fuel, utilities and personnel time. Capital costs included items such as vehicles, computers and furniture, and other items with a useful life of $>1$ year, these being annualised to reflect their annual value. The annual economic cost of capital items was calculated using a discount rate of $6 \%$ (the SA Reserve Bank's annualised rate), and all costs were adjusted to 2015 prices using the consumer price index. ${ }^{[15]}$ Useful life-years was 10 years for furniture, 3 years for vehicles and 4 years for office equipment and computers. ${ }^{[15]}$ The

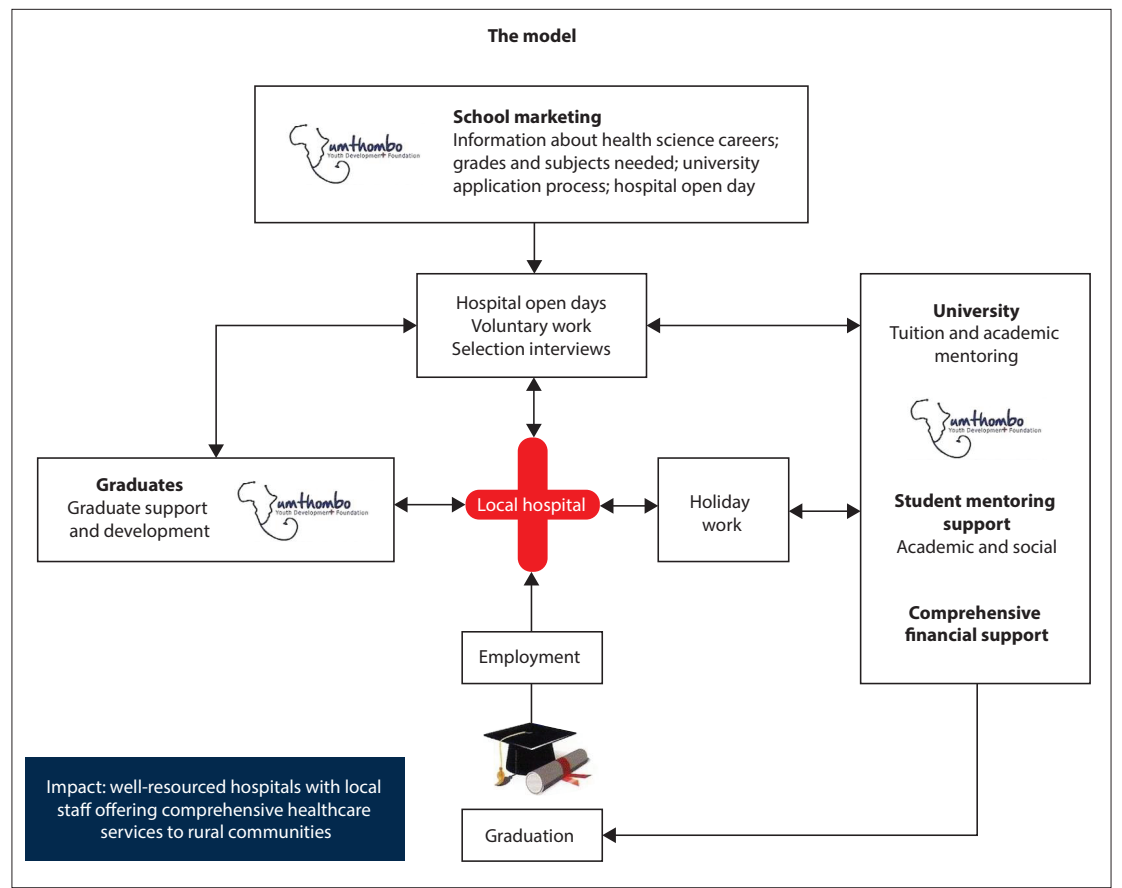

Fig. 1. UYDF education and employment model. ${ }^{[14]}(U Y D F=$ Umthombo Youth Development Foundation.)

6 cost-centre costs were aggregated into a total project cost and divided by the number of students in each year to obtain an annual average cost of supporting a student, the costing and modelling being done using Excel 2010 (Microsoft, USA).

The annual wage streams for the various cadres of health personnel produced by the UYDF were estimated over the expected working life of all graduates. An assumption was made that the average medical graduate will start work at 26 years of age, dental graduate at 24 years, and general health science graduate (4-year programmes) at 22 years, and that they would all retire at 65 years of age. No adjustment was made for normal employment attrition, promotion or specialist training. The salary data for public health workers in 2015, obtained from the Department of Public Service and Administration, ${ }^{[16]}$ were used to calculate wage streams for each discipline, assuming an annual increase of $5 \%$. Using these figures, the financial return on investment was calculated as the lifetime earnings of graduates compared with the costs of their training. The internal rate of return (IRR) and the net present value (NPV) of the expected benefits were calculated. IRR measures the efficiency of an investment and can be used to assess its profitability, ${ }^{[17]}$ with higher IRRs indicating the more desirable an investment is likely to be. NPV allows for the expression of future costs and benefits in terms of current prices, with a discount rate of $6 \%$ being used, and income taxes payable on lifetime earnings being estimated at an average tax rate of $30 \%$. The returns on investment are presented as two scenarios, the first using the UYDF average annual pass rate of $92 \%$ between 2012 and $2015^{[13]}$ to estimate the return on investment, while the second used the national pass rate of $42 \% \cdot{ }^{[18]}$ Total costs, lifetime earnings, and NPV of investments were calculated.

There was no ethics application, as this was a desktop analysis and all data were available on the UYDF database.

\section{Results}

Over the 7-year period 2009 - 2015, 254 of 276 (92\%) students supported by the UYDF graduated. During this time, the UYDF provided $\sim 166$ bursaries a year, their estimated annual cost being ZAR17 million (Table 1), of which $\sim 77 \%$ was spent on education support, $14 \%$ on administration and $7 \%$ on mentorship. The average education support amount per student per year amounted to ZAR78 600, which consisted of tuition fees of ZAR42 000, accommodation of ZAR19 000, meals of ZAR13 000 and books of ZAR4 600 . Mentorship totalled ZAR7 368 per student, and the costs, including recruitment, student support and administration, amounted to ZAR102 015 per student per year (Table 1).

Most of the graduates were medical doctors $(n=79), 32$ were nurses, 20 physiotherapists and 20 radiographers. The cost per discipline 
is presented in Table 2, as is the total cost of training all 254 graduates estimated at ZAR186 million.

These 254 graduates are expected to generate $\sim$ ZAR15 billion in lifetime earnings, which would be equal to ZAR4 billion at current prices (Fig. 2). The IRR on this investment is $63 \%$, and the income tax paid on future earnings will be $\sim$ ZAR4 billion, assuming a 20 $30 \%$ tax rate.

Over the past 6 years (2012 - 2016), the UYDF has been successful in helping underprivileged youth from rural areas to graduate from university, achieving a pass rate of $92 \% \cdot{ }^{[19]}$ This is in comparison with the Department of Higher Education and Training (DHET) report, which followed up cohorts of first-time undergraduate entrants between 2000 and 2008, showing that the 2008 cohort had throughput rates of $42 \%$ after 4 years and $61 \%$ after 6 years. ${ }^{[18]}$ Table 3 presents the costs adjusted according to the reduced DHET throughput rates. In this scenario, only 130 students graduated, with potential lifetime earnings of ZAR15 billion (estimated in Table 2) being reduced to ZAR8.4 billion (or ZAR2.2 billion instead of ZAR4 billion at 2019 prices).

The potential losses are not only in terms of lifetime earnings, but also the 'waste' of resources that could have been spent supporting students who would have succeeded and graduated. In this scenario, 124 students would not have graduated, which equates to ZAR84 million spent supporting students who did not graduate (124 students $\times$ ZAR676 858 per year for a 4-year degree). This
ZAR84 million represents the lost opportunity cost to society, as these resources could have been invested in alternative ventures that could have yielded future benefits. Further, ZAR6.6 billion is lost in lifetime earnings as a result of the lower pass rate and fewer graduates.

\section{Discussion}

The IRR on the ZAR186 million investments in HCPs' education is $63 \%$, which is much higher than the interest rates on commercial

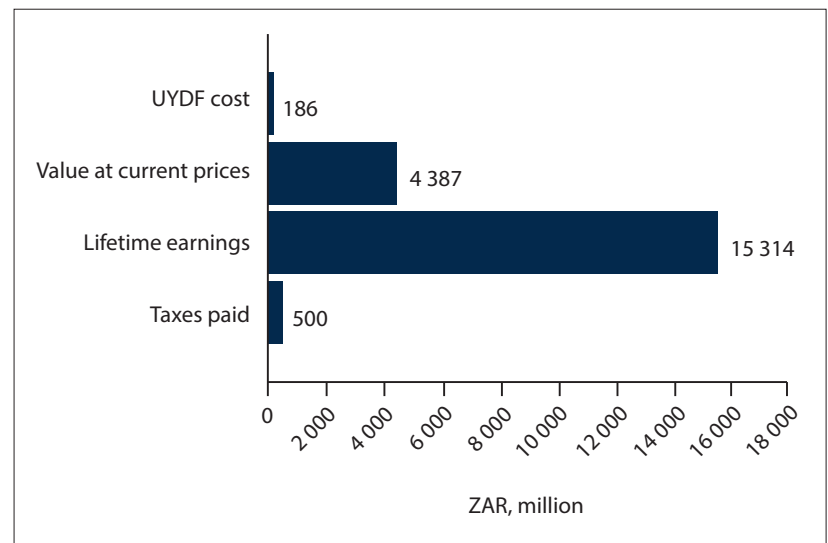

Fig. 2. Return on investment for UYDF graduates. (UYDF = Umthombo Youth Development Foundation.)

\begin{tabular}{llll}
\multicolumn{2}{l}{ Table 1. Total and average annual costs of supporting students, 2015 prices } \\
\hline Cost centre & Total cost, ZAR & Cost per student, ZAR & Total cost, \% \\
\hline Recruitment & 109821 & 663 & 0.6 \\
Education support & 13022407 & 78583 & 77.0 \\
Mentorship & 1221051 & 7368 & 7.2 \\
Postgraduate support & 101842 & 615 & 0.6 \\
Administration & 2273861 & 13722 & 13.5 \\
Capital costs & 176301 & 1064 & 1.0 \\
Estimated cost per year & 16905283 & 102015 & 100
\end{tabular}

Table 2. Costs and benefits of UYDF graduates, 2015 prices

\begin{tabular}{|c|c|c|c|c|c|}
\hline Disciplines & Graduates, $n$ & Total cost, ZAR & Lifetime earnings, ZAR & NPV & IRR, \% \\
\hline Biomedical technology & 14 & 8047815 & 542987675 & 155508210 & 52 \\
\hline Clinical associate & 1 & 574844 & 37667577 & 10787754 & 51 \\
\hline Dental therapy & 9 & 5173595 & 329530887 & 94375546 & 50 \\
\hline Dentistry & 4 & 3115493 & 380556795 & 108989041 & 90 \\
\hline Dietetics & 8 & 5414868 & 320499764 & 91789090 & 46 \\
\hline Environmental health & 1 & 676859 & 39980080 & 11450040 & 46 \\
\hline Medicine & 79 & 69590138 & 7539302053 & 2159208063 & 81 \\
\hline Nursing & 32 & 21659474 & 980647587 & 280851220 & 37 \\
\hline Nutrition & 1 & 676859 & 41804317 & 11972490 & 48 \\
\hline Occupational therapy & 5 & 3384293 & 198093126 & 56732609 & 46 \\
\hline Optometry & 12 & 8122303 & 479754305 & 137398576 & 46 \\
\hline Pharmacy & 19 & 12860312 & 1497155785 & 428775876 & 86 \\
\hline Physiotherapy & 20 & 13537171 & 798263387 & 228617547 & 46 \\
\hline Psychology & 7 & 4738010 & 578601746 & 165707853 & 90 \\
\hline Radiography & 20 & 13537171 & 798263387 & 228617547 & 46 \\
\hline Social work & 14 & 9476020 & 431033007 & 123445106 & 37 \\
\hline Speech therapy & 8 & 5414868 & 320499764 & 91789090 & 46 \\
\hline Total & 254 & 186000091 & 15314641244 & 4387131017 & 63 \\
\hline
\end{tabular}




\begin{tabular}{llll}
\multicolumn{2}{l}{ Table 3. Scenario analysis applying DHET pass rates to UYDF data } & & \\
\hline Disciplines & Graduates, $\boldsymbol{n}$ & Total cost, ZAR & Lifetime earnings, ZAR \\
\hline Biomedical technology & 6 & 8047815 & - \\
Clinical associate & 0 & 574844 & 10904 \\
Dental therapy & 4 & 5173595 & 146458172 \\
Dentistry & 2 & 3115493 & 190278398 \\
Dietetics & 4 & 5414868 & 160249882 \\
Environmental health & 0 & 676859 & - \\
Medicine & 52 & 69590138 & 4962578567 \\
Nursing & 15 & 21659474 & 459678556 \\
Nutrition & 0 & 676859 & - \\
Occupational therapy & 2 & 3384293 & 79237250 \\
Optometry & 5 & 8122303 & 199897627 \\
Pharmacy & 9 & 12860312 & 709179056 \\
Physiotherapy & 9 & 13537171 & 359218524 \\
Psychology & 3 & 4738010 & 247972177 \\
Radiography & 9 & 13537171 & 359218524 \\
Social Work & 6 & 9476020 & 184728432 \\
Speech therapy & 4 & 5414868 & 160249882 \\
Total & 130 & 186000091 & 8451654050 \\
DHET = Department of Higher Education and Training: UYDF $=$ Umthombo Youth Development Foundation. &
\end{tabular}

loans, indicating that the UYDF is a highly efficient programme. For example, the types of IRRs that would be considered satisfactory in commercial settings might be $10 \%$ for acquiring a stabilised asset, $15 \%$ for acquiring and repositioning an ailing asset, $20 \%$ for developing in established areas and 35\% for developing in an unproven area. Furthermore, the estimated income tax paid as qualified HCPs will be $\sim$ ZAR4 billion. This highlights that the initial UYDF investment of ZAR186 million is very small compared with the returns that will be paid several times over. A significant amount of money generated by these graduates is also likely to be used locally to better their livelihoods and those of their families, creating a ripple effect that contributes to local economic activity and additional employment opportunities in the district. It is clear from the data presented that the money spent on HCPs' education renders an excellent return on investment, and should be seen as such and not as an expense per se. However, it is also clear that such a return on investment is dependent on: (i) the percentage of students who pass and graduate from university; and (ii) the percentage of students who find employment after graduating.

It is essential that creative solutions be found to address the high attrition and low throughput rates at institutions of higher learning (IHL) in SA if the economic and social returns of education are to be realised. The IHL have responded to the challenges associated with poor basic education in SA and high attrition rates, with many having developed academic support programmes to address deficiencies in the schooling system. They have also designed bridging programmes to respond to the gap between competence of the student when they arrive at IHL and the expectations of institutions, and established foundation courses that extend the curriculum by an additional year. ${ }^{[20-23]}$

The criticism of these initiatives lies in the fact that they cater only for a minority of the student body and are not integrated into the curriculum. In the 2012 academic year, only 13000 students participated in extended programmes, representing $14 \%$ of students enrolled at IHL, whereas the enrolment of black students, who are likely to benefit from such programmes, accounted for two-thirds of the intake at IHL. ${ }^{[20-23]}$ A further criticism of these programmes is that they work from a deficiency model, are often reactionary, only responding when problems are identified, and do not fundamentally change the approach to teaching and learning at university. ${ }^{[20,21]}$ A study by $\mathrm{Scott}^{[23]}$ reveals that extended programmes, bridging programmes and mentoring may also inadvertently perpetuate a perception of inferiority among students, as it is mainly black, disadvantaged students who participate in these programmes. Hidden messages are sent to these students that they are weak, disadvantaged and likely to fail, which lead to resentment and non-participation in the programmes designed to help students, many of whom are on the brink of educational failure at university. ${ }^{[20]}$

The UYDF model is an example of what can work, albeit at a local level. It has a 19-year track record of supporting rural students at university, and over the past 6 years achieved a $92 \%$ annual pass rate, with $>337$ graduates working in the healthcare sector at the end of 2017. The success rate of UYDF students at university has mainly been attributed to the timely provision of financial support (food and book allowances) and its mentorship programme. The programme provides all students with support to enable them to address both academic and social pressures, and creates a system of accountability, holding them accountable to address their challenges. ${ }^{[14]}$ It is a proactive, compulsory mentorship programme, rather than optional ad hoc support that holds all students accountable for their own academic progress and success. ${ }^{[25]}$

The estimated cost of the UYDF mentorship programme is ZAR7 400 per student per year (2015 cost: 7\% of the total cost) and is a critical contributor to the annual pass rate of $>90 \%$. The lessons learnt through the UYDF mentoring programme or similar initiatives, if applied on a national level, could have a considerable impact on throughput at universities and on the economy of SA. In 2013 , there were $\sim 1$ million ( $n=1103639)$ students in higher education institutions, and a further 1 million in further education and training (FET) and adult education and training (AET) institutions. A total of 283622 of these students were studying sciences, engineering and technology (which includes all the health sciences). ${ }^{[26]}$ Of the 283622 science students, 127000 would have graduated at a pass rate of $45 \%$ compared with 264000 if the pass rate was $92 \%$, with lifetime earnings of ZAR8 trillion and ZAR15 trillion, respectively. Therefore, society stands to lose $\sim$ ZAR7 trillion in earnings over the next few years if the pass rates remain at $45 \%$ (compared with $92 \%$ ). 
Based on the UYDF experience, for an additional investment of ZAR7 400 per student per year in mentorship ( ZAR10 billion for 284000 students over 5 years), it is possible that the numbers of graduates in SA could more than double over a 5-year period (from 127000 to 264000 ) and the lifetime earnings could potentially increase from ZAR8 trillion to ZAR15 trillion. The NPV of this would also double from $\sim$ ZAR2.5 trillion to $\sim$ ZAR5 trillion, while the income tax on this difference would be $\sim$ ZAR500 billion, much larger than the initial investment in education. The possible contribution to the economy, and in decreasing unemployment, would therefore appear to be overwhelming.

According to a recent Statistics $\mathrm{SA}^{[27]}$ report, the unemployment rate in the fourth quarter of 2018 was $27.1 \%$, with graduate unemployment being $1.7 \%$. With the contradictions of high unemployment rates and a skills shortage in SA, it is essential that IHL equip graduates with appropriate skills relative to the job market to enable them to take advantage of the opportunities, and to contribute to growing the economy. Not finding employment represents a failure of IHL and a considerable loss to the SA fiscus.

In 2010, there were 106518 public sector vacancies for 14 categories of $\mathrm{HCPs},{ }^{[7]}$ which is another reason why the UYDF has specifically focused on addressing the shortages in specific disciplines. This has ensured that $98 \%$ of those supported found employment after graduation. ${ }^{[19]}$ This was facilitated by ensuring that all UYDFsupported students undertake annual work at local district hospitals to ensure that they are prepared for the job market. ${ }^{[14]}$

Finding permanent employment in the healthcare sector has transformed the lives of individuals supported by the UYDF, as well as the lives of their families, and more importantly, it has created a sustainable pool of HCPs who can contribute to the wellbeing of rural communities. ${ }^{[19,25]}$ As SA grapples with the problem of staffing in rural areas, the UYDF model provides evidence of what works in developing a critical mass of HCPs. The UYDF has produced 254 graduates from disadvantaged backgrounds between 1999 and 2015, which increased to 337 at the end of 2017, many of whom would otherwise not have had an opportunity to study at university. ${ }^{[13,19]}$ The success of the programme lies in the fact that it has holistically assisted many disadvantaged youth to successfully navigate tertiary education, graduate and serve in the public sector in rural communities. ${ }^{[14]}$

\section{Study limitations}

A limitation was the use of a deterministic model that did not fully capture the dynamic nature of investment in higher education. Although attrition rates are applied, re-entry was not considered, which has implications for costs and future benefits. Downstream attrition in the form of deaths and exit from employment was also not taken into account, which could potentially reduce the attractiveness of the investment. In this scenario, the DHET pass rate of $42 \%$ was applied to the total graduate numbers, and not broken down by health science discipline, which may affect the lifetime earnings calculated.

\section{Conclusions}

We believe that UYDF data demonstrate that health education is an economic investment and not merely an expense. The cost-benefit analysis has shown that the investment in rural youth to study for health science degrees renders a multifactorial return, and through income received and taxes paid contributes to the socioeconomic development of the individual, their community and the country. We believe that a focused, proactive, compulsory mentoring support programme, implemented nationally, could transform the pass rate and contribute significantly to the gross domestic product (GDP) for as little as $10 \%$ of the total educational expense per student. Although this research paper is based on one specific case study, we believe that the findings can be generalised with regard to other settings, and highlight the potential of what can be achieved if the UYDF model is implemented countrywide.

\section{Declaration. None.}

Acknowledgements. We acknowledge the valuable contributions to this manuscript of all employees of the UYDF. We also acknowledge the support of the UYDF funders. Without them, the data used in this article would not have been available.

Author contributions. LC, RGM: conception, data collection, analysis, interpretation and report; GZ, RGM, AJR: article development, revision and submission.

Funding. None.

Conflicts of interest. None.

Data availability. All relevant data in the article are available from the corresponding author on request. 1. Pillay-van Wyk V, Msemburi W, Laubscher R, et al. Mortality trends and differentials in South Africa from
1997 to 2012: Second National Burden of Disease study. Lancet Glob Health 2016;4(9):e642-e653. https:// doi.org/10.1016/S2214-109X(16)30113-9

2. Benatar S, Sullivan T, Brown A. Why equity in health and in access to health care are illusive: Insights from Canada and South Africa. Glob Publ Health 2017;2744-2760. https://doi.org/10.1080/17441692.2 017.1407813

3. Van Rensburg CJH. South Africas's protracted struggle for equal distribution and equitable access - still not here. Hum Resource Health 2014;12:26. https://doi.org/10.1186/1478-4491-12-26

4. Econex. Identifying the Determinants of and Solutions to the Shortage of Doctors in South Africa: Is There a Role for the Private Sector in Medical Education? Pretoria: Hospital Association of Sout Africa, 2015 .

5. Moyimane BM, Matlala FS, Kekana PM. Experiences of nurses on the critical shortage of medical equipment at a rural district hospital in South Africa: A qualitative study. Pan Afr Med J 2017;28:100. https://doi.org/10.11604/pamj.2017.28.100.11641

6. Hamilton K, Yau J. Global tug-of-war for health care workers. 2004. http://www.migrationpolicy.org/ article/global-tug-war-health-care-workers (accessed 18 December 2018).

Human Resources for Health South Africa. HRH strategy for the Health Sector 2012/3-2016/7. Pretoria: National Department of Health, 2011.

8. World Health Organization. A Universal Truth: No Health Without a Workforce. Geneva: WHO, 2013. Van Aardt CJ, Olivier R. Research and Development of a Higher Education Price Index for South Africa. Pretoria: Bureau of Market Research, College of Economic and Management Sciences, UNISA, 201

10. Motala S. Achieving free education for the poor - a realisable goal in 2018? J Educ 2017:68-73.

11. Academy of Science of South Africa. Reconceptualising Health Professions Education in South Africa: Consensus Study Report. Pretoria: ASSAf, 2018.

2. Ross A, MacGregor G, Campbell L. Review of the Umthombo Youth Development Foundation scholarship scheme, 1999 - 2013. Afr J Prim Health Care Fam Med 2015;7(1):1-6. https://phcfm.org index.php/phcfm/article/view/739

13. MacGregor RG. Umthombo Youth Development Foundation Annual Report 2015/16. Durban: Umthombo Youth Development Foundation, 2016.

14. MacGregor RG, Ross AJ, Zihindula G. A Rural Scholarship Model Addressing the Shortages of Healthcare Workers in Rural Areas. South African Health Review. Durban: Health Systems Trust, 2018:49-55.

15. Statistics South Africa. Consumer price index (CPI) history. 2016. http://www.statssa.gov.za/?page_ id=1871 (accessed 12 June 2016).

16. National Treasury. Estimates of national expenditure. 2018. http://www.treasury.gov.za/documents/ national\%20budget/2018/enebooklets/Vote\%2010\%20Public\%20Service\%20and\%20Administration pdf (accessed 12 June 2018).

17. Ermenyi T. Evaluating investment profitability and business controlling methods. J Econ Lit 2015:183-198.

18. Department of Higher Education and Training. 2000 - 2008. First Time Entering Undergraduate Cohort Studies for Public Higher Education Institutions. Pretoria: DHET, 2016.

19. MacGregor RG. Umthombo Youth Development Foundation Annual Report. Durban: UYFD, 2017.

20. Davidowitz B, Schreiber B. Facilitating adjustment to higher education: Towards enhancing academic functioning in an academic development programme. S Afr J High Educ 2008;22(1):191-206. https://doi. org/10.4314/sajhe.v22i1.25781

21. Dhunpath R, Vithal R. Alternative Access to Higher Education. Cape Town: Pearson Education, 2012.

22. Letseka M, Cosser M, Breier M, Visser M. Student Retention and Graduate Destination: Higher
21. Education and Labour Market Access and Success. Pretoria: Human Sciences Research Council, 2009. Scott I. Access, success and curriculum: Aspects of their organic relationship. In: Dhunpath R, Vithal R, eds. Alternative Access to Higher Education. Cape Town: Pearson Education, 2013

24. Lubben F, Davidowitz B, Buffler A, Allie S, Scott I. Factors influencing access students' persistence in an undergraduate science programme: A South African case study. Int J Educ Develop 2010;30(4):351-358. https://doi.org/10.1016/j.ijedudev.2009.11.009

25. Ross AJ. From rural scholar to health care professional. S Afr Fam Pract 2015;1(1):1-6. https://doi.org/1 $0.1080 / 20786190.2015 .1071537$ 26. Department of Higher Education and Training. Foundation Provision in Ministerial Approved Programmes.
Pretoria: DHET, 2015.

27. Statistics South Africa. Country Annual Report on Education and Employment. Pretoria: StatsSA, 2018. 